Revista de Negócios_ISSN 1980.4431_vol. 19, n. 2, p. 21_35, 2014_DOI:10.7867/1980431.2014v19n2p21_35

\title{
Conhecimentos e habilidades de comunicação para empreendedores nas fases iniciais do ciclo de vida organizacional de Adizes
}

\section{Knowledge and communication skills to entrepreneurs in the early stages of the organizational life cycle of Adizes}

\author{
Eduardo de Carli \\ UFPR Universidade Federal do Paraná - Brasil \\ eduardodecarli@yahoo.com.br \\ Alexandre Meira Vasconcelos \\ Universidade Federal do Mato Grosso do Sul - Brasil \\ alexandremeira@ufms.br \\ Álvaro Guillermo Rojas Lezana \\ UFSC Universidade Federal de Santa Catarina - Brasil \\ lezana@deps.ufsc.br
}

Recebido em 12 de agosto de 2013. Alterado em 13 de janeiro de 2014. Aprovado em 22 de abril de 2014

Editor Responsável: Edson Roberto Scharf, Dr.

Processo de avaliação por double blind review

\section{Resumo}

Este artigo identifica as habilidades e conhecimentos de comunicação necessários ao empreendedor durante as fases de crescimento do ciclo de vida organizacional de Adizes (2004): Namoro, Infância, Toca-toca, Adolescência e Plenitude Inicial. Trata-se de um estudo teórico prescritivo baseado no modelo de CVO de Adizes e em artigos teórico-empíricos sobre comunicação e empreendedorismo. Observou-se que, em cada etapa, o empreendedor deve acessá-la e/ou desenvolvê-la para que a organização sobreviva e avance para fases posteriores. Destaca-se que, nas fases iniciais do ciclo em questão, a comunicação está centrada na figura do empreendedor e, aos poucos, se torna mais profissional, formal, integrada e mediada por tecnologias, o que evidencia que a evolução da comunicação acompanha o desenvolvimento pessoal e profissional do empreendedor e seu empreendimento. $\mathrm{Na}$ fase de Namoro, a comunicação concentra-se no compartilhamento de ideias e sentimentos com o objetivo de angariar adeptos de seus ideais. Na Infância, a comunicação ocorre do empreendedor para seus subordinados principalmente de forma oral, face a face, uma vez que há pouca hierarquia. $\mathrm{Na}$ fase Toca-Toca, há a continuidade do segundo estágio, a empresa apresenta-se em ascensão, de forma rápida, porém desordenada, e as tarefas do dia-a-dia são desempenhadas crise após crise. $\mathrm{Na}$ fase de adolescência organizacional, a empresa está em um período de desenvolvimento, no qual acontece a profissionalização, a delegação de funções e uma maior interdependência dos setores. Na Plenitude Inicial do empreendimento há equilíbrio, com sistemas bem estruturados, e a característica fundamental de comunicação está relacionada à 
Conhecimentos e habilidades de comunicação para empreendedores nas fases iniciais do ciclo de vida organizacional de Adizes

formalização de procedimentos, para assegurar informações suficientes para o desempenho das atividades, de forma clara e objetiva. Um quadro síntese é apresentado ao final do artigo com os conhecimentos e habilidades de comunicação necessários a cada fase do ciclo.

Palavras-chave: Empreendedorismo; comunicação organizacional; ciclo de vida organizacional, modelo de CVO de Adizes, conhecimentos e habilidades.

\begin{abstract}
This article identifies the communication skills and knowledge necessary to the entrepreneur during the growth phase of the organizational life cycle of Adizes (2004): Courtship, Infancy, Go-go, Adolescence and Prime. This is a theoretical prescriptive study based on OLC model of Adizes and theoretical and empirical articles on communication and entrepreneurship. It was observed that, at each stage, the entrepreneur must access it and / or develop it for the organization to survive and advance to the later stages. It is noteworthy that, in the early stages of the cycle in question, communication is focused on the entrepreneur and gradually becomes more professional, formal, integrated and mediated by technology, which shows that the evolution of the communication accompanying the personal and professional development of the entrepreneur and his venture. In the phase of Courtship, communication focuses on sharing ideas and feelings with the goal of raising supporters of their ideals. At Infancy, communication occurs by the entrepreneur for his subordinates mainly orally, face to face, since there is little hierarchy. In phase Go-go, there is continuity of the second stage, the company presents itself on the rise, quickly, but disordered, and the tasks of day-to-day are performed crisis after crisis. At the stage of organizational Adolescence, the company is in a period of development, in which case the professionalization, delegating roles, and greater interdependence of sectors. At the Prime, development is balanced with well-structured systems, and the key feature of communication is related to the formalization of procedures, to ensure sufficient information for the performance of activities, clearly and objectively. A summary table is provided at the end of the article with the communication knowledge and skills needed at each stage of the cycle.
\end{abstract}

Palavras-chave: Entrepreneurship, organizational communication, organizational life cycle, OLC model of Adizes, knowledge and skills.
Em uma empresa, a comunicação consiste em um "conjunto de métodos e técnicas [...] dirigida ao público interno (funcionários) e ao público externo (clientes, fornecedores, consumidores etc.)" (FIGUEIREDO; NASSAR, 2007, p.18). Incluem-se elementos de comunicação, tais como: as relações interpessoais e o modo como consumidores e a sociedade em geral percebem a empresa. Para Metallo et al. (2007), na indústria, a comunicação é basicamente técnico-funcional, mas, mesmo assim, a equipe de vendas tem de manter excelentes relações interpessoais com os clientes. Em razão disso, conclui-se que a comunicação empresarial é o entendimento e transformação da realidade que a cerca, ou seja, a expressão, o repasse dessa realidade percebida e transformada.

Para a efetiva funcionalidade deste sistema produtivo, precisa-se que a organização se comunique, a priori, internamente, para garantir o desempenho das atividades e, a posteriori, externamente, para interagir com os consumidores dos produtos e serviços e, além disso, adequar sua produção aos objetivos estratégicos organizacionais. Bartolomé (1989) afirma que a comunicação é um meio para fornecer feedback, explicar políticas organizacionais e decisões do staff gerencial, desde que, de forma ética, se evite usar as informações como instrumento de manipulação ou recompensa.

O conceito de "ciclo de vida" de organizações é usado desde os anos 50 para modelar e compreender o crescimento e desenvolvimento de empresas de toda natureza. Phelps et al. (2007) listam mais de trinta modelos de 1967 a 2003. Embora com diferentes abordagens, alguns modelos se destacaram no meio acadêmico por explicarem a realidade de maneira mais fiel e adequada. Destacam-se os modelos de Greiner (1975), Churchill e Lewis (1983), Scott e Bruce (1987),

\section{Introdução}


Adizes (2004), que têm em comum (1) a evolução das empresas por uma sequência natural; (2) que a progressão não é facilmente revertida; (3) envolvem uma ampla gama de atividades organizacionais em cada estágio (GUPTA e CHIN, 1994). A cada etapa, o empreendedor precisará utilizar diferentes ferramentas e formas de comunicação para evoluir e avançar no ciclo de vida.

Neste sentido, este artigo tem o objetivo de identificar conhecimentos e habilidades de comunicação do empreendedor nas fases iniciais do ciclo de vida organizacional de Adizes (2004). O estudo centra-se na figura do empreendedor porque é ele quem inicia o negócio, quem tem a ideia, quem propicia a "destruição criativa" (SCHUMPETER, 1983), é quem provoca o desequilíbrio no fluxo circular da produção, é quem garante a inovação no decorrer do processo produtivo. Este indivíduo é o impulsionador do movimento capitalista ao criar produtos novos, inovar os meios e métodos de produção, atingir novos mercados, de maneira mais rápida, mais barata e com maior qualidade (SCHUMPETER, 1983). O estudo também é centrado nas fases iniciais do ciclo de vida organizacional de Adizes (2004) porque nelas a participação do empreendedor é mais direta, mesmo quando mediada por terceiros ou por tecnologias, e a empresa tem um porte menor, o que possibilita identificar e acionar com mais clareza as competências de comunicação requeridas. Em um estudo sobre as barreiras de implantação de tecnologias de informação e e-business em pequenas indústrias na India, Ram e Selvaraj (2012) concluíram que parte do insucesso dessa empreitada está nos estereótipos sobre a agilidade das tecnologias e da possibilidade de tomar decisões em tempo real, com o intuito de atender às necessidades dos clientes e aumentar a competitividade. Entretanto, estes autores alertam que implantar tecnologias de informação não é um processo simples, pois requisitos de comunicação devem ser analisados, riscos calculados e enfrentados, restrições devem ser estudadas e as metas bem estabelecidas.

$O$ modelo de ciclo de vida organizacional (CVO) desenvolvido por Adizes (2004) consiste em uma metáfora da evolução natural de seres vivos sobre o desenvolvimento organizacional. Seu enfoque descreve as organizações quanto ao estágio evolutivo, com o intuito de compreender a fase atual, propor soluções a problemas do passado, antecipar situações futuras e se preparar para elas. Este nível de compreensão do estágio presente possibilita que as organizações se mantenham competitivas, em constante evolução e em condições de propor estratégias adequadas à situação da organização.

A comunicação é fundamental para a integração entre todas as áreas da empresa, para que a transmissão de informações favoreça a eficiência do trabalho e a consequente melhoria do processo produtivo em todas as fases do ciclo de vida organizacional. A empresa e o empreendedor passam por estágios com características singulares e a capacidade do empreendedor de absorver novos conhecimentos e desenvolver novas habilidades é crucial para o sucesso empresarial (GRAPEGGIA; MINUZZI, 2008).

Metodologicamente, esta pesquisa é de cunho teórico, com abordagem qualitativa e exploratória. $\mathrm{O}$ viés qualitativo é identificado no caráter interpretativo dado pelos autores ao conteúdo e características de cada fase.

\section{Revisão Teórica}

Esta seção apresenta os resultados da revisão teórica sobre comunicação e sobre o ciclo de vida organizacional de Adizes (2004), eixos centrais deste estudo.

\subsection{A comunicação}


Conhecimentos e habilidades de comunicação para empreendedores nas fases iniciais do ciclo de vida organizacional de Adizes

As empresas são formadas por um conjunto dos recursos humanos, financeiros, físicos e de informação, organizados para atingir objetivos e a comunicação é um fator chave para interligá-los, para que a organização como um todo entenda o objetivo a seguir e que os recursos sejam canalizados para o mesmo sentido. Como exemplo, organizações que têm o capital intelectual como fator primordial de evolução recorrem a ferramentas de interação para propiciarem maior fluência e rapidez ao desenvolvimento, por meio de diferentes formas de comunicação, normalmente mediadas por recursos tecnológicos (FONSECA, 2005).

Uma das habilidades do empreendedor está centrada na condução de pessoas, nas relações interpessoais e de comunicação, uma vez que influencia o modo como envolve e trabalha com elas, na capacidade de conduzir, motivar e comunicar-se de modo eficaz. As habilidades de comunicação são essenciais para a interação dos empreendedores com os diversos stakeholders e estão ligadas fortemente às habilidades sociais: percepção do outro; gerar primeiras impressões favoráveis; capacidade expressar emoções (ULVENBLAD et al., 2013). Invernizzi et al. (2012) recorrem à teoria sobre empreendedorismo para revelar a importância estratégica da comunicação para gerenciar a mudança organizacional ao desenvolver e consolidar a cultura da empresa, por meio do envolvimento das pessoas, da orientação para a cultura de inovação, disseminação de objetivos, visão de futuro e valores, bem como da preparação para atuação no ambiente competitivo contemporâneo.

A comunicação é estabelecida pela troca de mensagens entre as partes e por intermédio de signos como palavras, sons, gestos e "é um produto funcional da necessidade humana de expressão e relacionamento" (BORDENAVE, 2006, p. 45-46): há um emissor, caracterizado como o iniciante do processo de transmissão da mensagem, via algum canal (oral ou escrito), para o receptor, que procura decodificá-la por intermédio da interpretação (ou identificação) de seu significado e, quando necessário, retorná-la (dar feedback). Para que tenha sentido, é preciso que seus agentes estejam interligados aos acontecimentos, ajam e mudem continuamente, propiciando o relacionamento interpessoal, com transformação da realidade e das pessoas (BORDENAVE, 2006), pois o ato de comunicar propicia alterações em pessoas, ambientes, sociedades, com a intenção de integrá-los. Existe também como ferramenta de troca de conhecimentos e competências, para transmitir informações que serão compartilhadas e terão significado para seus agentes, o emissor e $\mathrm{o}$ receptor. $\mathrm{O}$ processo de comunicação eficiente torna-se um dos principais elementos para condicionar a existência organizacional, que tende a ser duradoura a partir do momento que todos estejam interligados, se conectem aos objetivos da empresa. Devem utilizar o contato e a comunicação para compartilhar o conhecimento, visto que este é elemento de progresso mútuo, além de primordial para o desenvolvimento das tarefas. Para Li et al. (2011), os empresários e gestores de micro e pequenas empresas devem dar especial atenção às atividades de gestão do conhecimento, especialmente da comunicação, controle e exploração para incrementar as ações de inovação organizacional. Com base nestes ideais, o estudo discute como deve ocorrer o processo de comunicação durante o CVO, uma vez que é com base em tal processo que, assim como os seres humanos, que as organizações evoluem.

No caso do empreendedor, o estímulo para se comunicar provém do propósito de levar a cabo o negócio que concebeu e buscar a aproximação de potenciais parceiros para apoiá-lo em sua causa. Tal fato implica ao empreendedor em aprender a praticar a linguagem adequada aos seus interlocutores de 
maneira que sua mensagem os alcance e, ainda, a interpretar as respostas que lhe são dadas. Quanto à forma, as mensagens variam entre verbais e não verbais sejam por conversas com funcionários, encontros com clientes, negociações com fornecedores, solicitação de empréstimos, entre outras (ADEJIMOLA, 2008).

Nas organizações, a comunicação serve para transmitir informações, influenciar ações (FARIA, 2002) e para manter as relações internas dos elementos para alcançar maior disseminação do conhecimento e de habilidades para o desenvolvimento das funções. Busca-se garantir a vantagem competitiva que, na visão de Keller e Kotler (2006), significa qualidade, serviço, preço, personalização da mercadoria, melhoria contínua do produto e inovação. Ao empreendedor, a comunicação persuasiva é ferramenta fundamental, especialmente nos primeiros anos da existência de seu empreendimento, quando seu objetivo concentra-se em viabilizar suas ideias. Para corroborar, Lezana (1995) argumenta que é apenas uma ideia o que o empreendedor tem em mente quando inicia o negócio. Para tornála realidade, precisará convencer outras pessoas conhecidas ou desconhecidas de que a ideia é boa para que estas invistam recursos diversos, convencer financiadores a darem crédito e clientes a comprarem os produtos ou serviços. Também precisará convencer seus pares, família, amigos a aderirem ao negócio e a apoiarem em todos os sentidos para crescer (DELLA BRUNA JUNIOR et al., 2010). Para tanto, deverá acessar e usar de conhecimentos e habilidades de comunicação oral e escrita (LEZANA, 1995).

Assim, é notório que a comunicação é elemento primordial, pois é pelo convencimento das ideias do empreendedor que se determina o nascimento e a base do empreendimento. É também por meio da comunicação que se efetiva a sobrevivência da empresa e seu crescimento. A comunicação é um elemento importante na cadeia produtiva e é capaz de produzir um efeito real, que resultará muito provavelmente em vantagens financeiras e organizacionais, pois os elementos do sistema integrar-seão, chances de erros serão diminuídas, a comunicação entre as pessoas tornar-se-á mais efetiva, criando um ambiente mais saudável e profícuo.

Ao empreendedor cabe o papel de inovar, propiciar a "destruição criativa" (SCHUMPETER, 1983) e a comunicação tem papel importante no empreendimento, visto que contribui "para a modificação dos significados que as pessoas atribuem às coisas $\mathrm{e}$, através da modificação de significados, a comunicação colabora na transformação das crenças, dos valores e dos comportamentos" (BORDENAVE, 2006, p. 92). Para uma empresa, a comunicação é elemento indispensável para auxiliar em sua sobrevivência e evolução. $\mathrm{O}$ empreendedor precisa valer-se da comunicação eficaz para alcançar os objetivos a que propôs para si e para a organização, complementando-a, quando necessário, com as tecnologias disponíveis (ADEJIMOLA, 2008). Em relação às tecnologias de informação por meio de internet, Lee e Jones (2008) enfatizam que empresas que fazem negócios ou interações online e, portanto, ligadas a uma rede virtual, conseguem obter recursos mais elevados e sustentados para seu crescimento.

Algumas habilidades são fundamentais para que haja o efetivo desenvolvimento organizacional, como as apresentadas por Mintzberg apud Maximiano (2006), que consideram o fator humano e suas habilidades de relacionamento com colegas (capacidade de estabelecer e manter relações formais e informais); habilidades de empreender (busca de oportunidades e a implantação de mudanças organizacionais); habilidades de introspecção (capacidade de reflexão, ou seja, de aprender com a própria experiência); habilidades de processamento de informações (capacidade de aprender a construir redes informais e desenvolver 
Conhecimentos e habilidades de comunicação para empreendedores nas fases iniciais do ciclo de vida organizacional de Adizes

habilidades de comunicação). A vantagem competitiva concentra-se em como estas habilidades são geridas: a eficiente e eficaz comunicação nos diferentes níveis, desde a alta administração até as pessoas na produção, e vice-versa, quando considerada dentro da instituição (LEZANA, 1995). É primordial que a comunicação ocorra como um meio de integração, em todos os níveis e funções, pela transmissão de informações e, principalmente, como uma estratégia para a mudança de comportamento com vistas à realização pessoal e eficiente do trabalho. Para Hardy (2011), a institucionalização da comunicação implica em que a parte comunicada atenda e cumpra o que foi comunicado; que a mensagem alcance em número e tamanho a sua audiência; e que as mensagens sejam congruentes com os propósitos expressos pelos membros que se comunicam. 2.2 O ciclo de vida organizacional de
Adizes

O ciclo de vida organizacional de Adizes (2004) caracteriza-se por etapas de crescimento e etapas de envelhecimento (Figura 1), sendo estas últimas o principal diferencial do modelo, visto que alguns modelos tradicionais, anteriores a Adizes (2004) trataram somente do crescimento da organização (SCOTT e BRUCE, 1987; CHURCHILL e LEWIS, 1983; GREINER, 1975). Para Adizes (2004), há quatro papeis gerenciais: $\mathrm{P}$ (Produzir), A (Administrar), E (Empreender) e I (Integrar), que são "mutuamente incompatíveis e ameaçam um ao outro" e o desenvolvimento ou não de cada um deles define cada um dos estágios do modelo de ciclo de vida, sendo que a letra maiúscula indica que o papel é desenvolvido na fase.

Para o desenvolvimento deste artigo, também serão enfatizadas as etapas de crescimento por representarem a evolução desde a criação da empresa até sua maturidade organizacional. Entretanto, para fins de concepção teórico-conceitual, todas as etapas serão sucintamente descritas. Escolheu-se o modelo de Adizes (2004, p.173) por bem caracterizar quatro papéis do empreendedor de produzir, administrar, empreender e integrar, em cada fase evolutiva, que são "mutuamente incompatíveis e ameaçam um ao outro". Isso quer dizer que o desenvolvimento (ou não) de cada um deles define os estágios previstos em seu modelo de ciclo de vida. Evoluir no ciclo envolve a alteração da estrutura organizacional e implicam em obter diferentes recursos e definir prioridades estratégicas (LI, 2008).

Este artigo se sustenta na teoria de Adizes (2004) que concebeu um modelo generalista para explicar o desenvolvimento organizacional e estabeleceu características para cada uma das fases de desenvolvimento. O modelo desenvolvimentista baseado na metáfora da organização como um organismo vivo tem um forte apelo intuitivo em considerar o caráter de transformação das organizações desde seu nascimento até sua maturidade, reinvenção ou morte (PHELPS et al., 2007). Wang et al. (2007) apontam as principais observações dos críticos aos modelos assim concebidos: a) os pesquisadores não conseguem prever exatamente em qual fase uma organização está e quando se moverá para outro estágio; b) as características das fases não podem ser quantificadas, além de serem ambíguas; c) os negócios não precisam necessariamente crescer em uma perspectiva linear. Ainda que generalistas e passíveis de questionamentos, o uso da metáfora da organização como um organismo vivo para explicar o crescimento organizacional e as trocas que as empresas fazem nos ambientes em que estão inseridas têm respaldo na teoria dos sistemas (MORGAN, 1996).

Cada fase descrita por Adizes (2004) apresenta um conjunto de problemas e, em cada um deles, são exigidos conhecimentos, habilidades $\mathrm{e}$ atitudes específicas do empreendedor, que sempre desempenhará papéis diferentes: 
(1) Namoro, na qual o empreender é o fator principal, pois a organização ainda não foi criada. Trata-se de um movimento interno do empreendedor na construção do sonho de ter um negócio, pensando na possibilidade e viabilidade de efetivação de seus desejos empresariais. Corre-se o risco dele não querer ou não ter condições de levar a ideia adiante e o negócio não se concretizar. Nesta etapa só há uma ideia que surge do empreendedor, uma vez que a organização apenas existe como uma possibilidade do que possa vir a ser (como uma paixão cuja correlação é apresentada pelo namoro em relação ao casamento, em que há muito entusiasmo e empolgação por parte de quem os vive). $\mathrm{O}$ empreendedor vê em tal situação a possibilidade de realização de satisfação pessoal de suas necessidades. Por isso, acredita em seu ideal tendo em vista atingir o futuro, conquistar sua satisfação por meio da satisfação dos clientes. Isso implica em que, para a efetiva realização, há necessidade de assumir um compromisso e os riscos para a efetiva implantação da ideia, que pode vir a dar certo ou não (assim como o namoro que não vira casamento e é apenas tido como um caso amoroso). É preciso que a possível ação esteja centrada de acordo com a realidade, uma vez que neste estágio é apenas um ideal que está em jogo, e a empresa ainda não apresenta um valor "tangível". Para Ulvenblad et al. (2013), a dificuldade de ingressar em um mercado reside na falta de trajetória e de legitimidade do empreendedor.

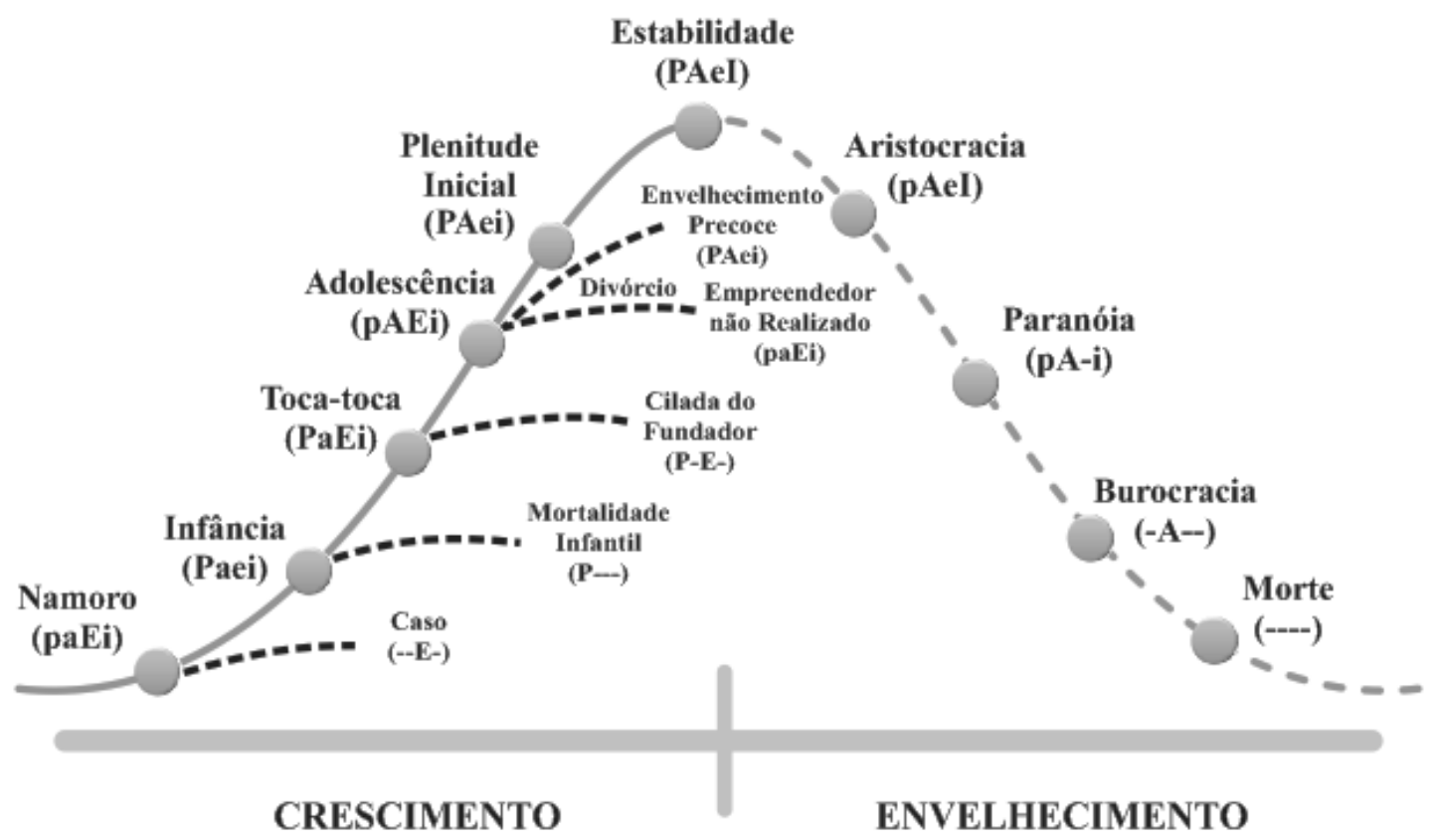

Figura 1 - Modelo de Ciclo de Vida de Organizações de Adizes

Fonte: Adaptado de Adizes (2004)

Surge a paixão pelo negócio nascente e é isso que motivará o empreendedor em momentos de dificuldade da fase (2), a Infância, com foco principal na produção e menos na venda de produtos. Nesta fase, o empreendimento sai do campo das ideias e torna-se realidade, mas o empreendedor está concentrado na solução de problemas de produção, de uso de tecnologia e desempenho do produto. Não percebe que deve dar atenção às vendas, sob pena de falir, como é comum nessa fase. A materialização do sonho exige 
Conhecimentos e habilidades de comunicação para empreendedores nas fases iniciais do ciclo de vida organizacional de Adizes

empreendedores atuantes, que dediquem muito tempo e trabalho à empresa nascente e tenham pouca ou nenhuma vida social, sob pena de acontecer o que Adizes chama de "mortalidade infantil". O foco na produção e não no mercado vem do compromisso emocional com a ideia e o bom desempenho do produto é o que motiva o empreendedor a enfrentar riscos. Ele confia na ideia e tem a confiança de que aquilo é uma oportunidade de negócio, e não se interessa no que o mercado necessita.

Na fase (3), chamada Toca-Toca, o crescimento da organização e a entrada de dinheiro em caixa desenvolvem a arrogância nos empreendedores. Estes passam a ver boas oportunidades em tudo e esperam bons resultados de todos. Tornamse orientados às vendas, mas sem planejálas. Como os sistemas de controle gerenciais ainda são incipientes, o empreendedor não pode afirmar se $o$ aumento das vendas representa aumento dos lucros, embora acredite que essa relação é verdadeira. Uma das formas que utiliza para motivar os clientes ao consumo é o marketing, pois espera levar maior conhecimento aos consumidores e, consequentemente, agregar maior valor ao que é disponibilizado. Esta estratégia é economicamente dispendiosa, toma grande parte dos recursos e afeta o desenvolvimento da empresa. Há maior dedicação às vendas do que ao controle de custos. $\mathrm{O}$ empreendedor espera que $\mathrm{o}$ mercado absorva o seu produto e a empresa sobreviva, e uma vez não ocorrendo, a organização estará fadada ao declínio e, possivelmente, à morte. $\mathrm{O}$ comportamento arrogante do empreendedor é a principal ameaça do negócio neste estágio.

No estágio (4), o da Adolescência, o papel de administrador começa a tomar vulto na organização, mas, para que isso realmente aconteça, o empreendedor deve começar a delegar, sem perder o controle. Torna-se difícil abrir mão do poder e independência que existia nos estágios anteriores e é necessário profissionalizar a gestão, contratando novos profissionais. Neste estágio, o empreendimento alcança bons níveis de vendas e de evolução e se torna integrado às necessidades e desejos dos clientes. A mudança na forma de gestão é inevitável, pois a presença ostensiva do empreendedor nas atividades não mais acontece, porém os conflitos de poder advindos desta decisão podem frustrar seus ideais ou gerar a falta de flexibilidade organizacional ("envelhecimento precoce").

A Plenitude Inicial, fase (5), caracteriza-se pelo equilíbrio não estável entre autocontrole e flexibilidade, pois estão em igualdade de importância as ações de produzir, administrar e empreender. Essa fase é caracterizada por alto crescimento, alto lucro, consciência sobre o que pode ou não ser feito, clareza e parcimônia na avaliação de oportunidades e foco em qualidade e produtividade. A plenitude é perdida concomitante à perda do espírito empreendedor. Quanto maior a adequação à realidade, maiores serão as chances da organização sobreviver e, não raro, se desenvolver até alcançar a Plenitude, considerada a última fase de crescimento do CVO.

As fases seguintes são de decréscimo e descritas como fase (6) Estabilidade, na qual o espírito empreendedor diminui e aumenta o foco nas pessoas. A organização é bem sucedida e começa a valorizar as relações internas e dá menos atenção a integração externa com o mercado; Aristocracia (7), os rituais internos ganham importância em um ambiente dominado por aspectos administrativos e integradores. A organização assume menos riscos e, por isso, o declínio do foco na produção e no empreendedorismo. A acomodação em um mundo em constante movimento tende a representar perda de clientes e cai o volume de vendas; Paranoia (8), os entraves burocráticos tendem a bloquear a organização e os líderes atuais são responsabilizados pela inércia reinante. Os 
conflitos interpessoais minam o clima organizacional a ponto de surgirem guerras internas. A Burocracia (9), ganha espaço em um ambiente predominantemente administrativo e é dissociada da relação com o ambiente externo. Intervenções externas, sejam de clientes ou não, são evitadas por meio de barreiras reais ou virtuais. Os rituais ganham mais status na organização, bem como a "veneração da palavra escrita". A Morte (10) ocorre quando não há mais motivos para realizar as ações da organização e não há motivos para produzir, administrar, empreender ou integrar.

\section{A comunicação no ciclo de vida organizacional de Adizes}

O desenrolar do processo de comunicação no CVO começa pela fase chamada Namoro, cuja comunicação concentra-se no compartilhamento de ideias e sentimentos (muitas vezes de modo repetitivo e contraditório em razão da paixão do empreendedor, que leva à desordem de pensamentos), por meio dos quais o empreendedor procura identificar seu sonho em como fazer para efetivamente estabelecê-lo, implantá-lo e transmiti-lo a quem o cerca, com o objetivo de angariar adeptos de seus ideais.

$\mathrm{Na}$ segunda fase, a Infância, a comunicação ocorre do empreendedor para seus subordinados principalmente de forma oral, face a face, uma vez que há pouca hierarquia e faz-se preciso um retorno imediato da informação, sendo ela mais direta e persuasiva. É o início da operacionalização da empresa, que possui poucos funcionários e tem $\mathrm{o}$ perfil do empreendedor como perfil do negócio. Os poucos funcionários realizam todo o tipo de atividades para auxiliar o empreendedor, o que acarreta em forte adesão à empresa, maior grau de informalidade (comunicação informal, que remete à maior amizade entre os participantes) e controle total da empresa pelo empreendedor (do conjunto de processos para a realização de atividades). Estas características constituem fatores críticos para a operação e sucesso organizacional: flexibilidade, agilidade e rapidez para correção da rota, ambiente interno da ação, baixos recursos, tornandose necessária uma comunicação eficiente, pois, com a escassez de recursos, há que minimizar os erros e, para que isto aconteça, o empreendedor deve se interrelacionar com os subordinados, determinar o que deve ser feito: o lema desta fase é "faça agora". Para Adejimola (2008), não há possibilidade de sucesso sem haver comunicação humana no interior da organização.

Em empresas de base tecnológica, onde grande parte dos empreendedores provém de cursos de nível superior como engenharia e tecnologia da informação, pode haver problemas de comunicação causados pela formação desses indivíduos, como alertam Messerschmitt e Stuck (2008), uma vez que nesses cursos parece haver uma tendência de formar pessoas que crêem que a tecnologia é um fim em si mesma e costumam desconsiderar ou menosprezar disciplinas de cunho social ou de linguagem. Na terceira fase, a TocaToca, há a continuidade do segundo estágio, a empresa apresenta-se em ascensão, de forma rápida, porém desordenada, e as tarefas do dia-a-dia são desempenhadas crise após crise. Devido a isso, ocorrem falhas na comunicação:

\footnotetext{
“[...] as pessoas fazem exigências, haja ou não quem lhes possa atender. Espera-se que todos dêem o melhor de si, mas, não importa o que façam, estão sempre aquém do que esperam os arrogantes fundadores. Palavrões são padrões de expressão" (ADIZES, 2004, p. 122).
} 
Conhecimentos e habilidades de comunicação para empreendedores nas fases iniciais do ciclo de vida organizacional de Adizes

Para Foote (2013), a liderança precisa pensar estrategicamente, avaliar as informações disponíveis, possíveis danos e impactos sobre os stakeholders, agir e comunicar-se ainda que com informações incompletas e encontrar os fluxos de informação simétricos ou bidirecionais. A comunicação desordenada resulta em um ambiente ruim de trabalho, causa dispersão do controle das atividades e desordem de ações que, por conseguinte, ocasiona o desânimo dos colaboradores e intrigas. Todos procuram se sobressair no desempenho das atividades para, no final, por melhor que as tenham desenvolvidas, não serem reconhecidos pelos superiores, aumentando ainda mais os problemas de relacionamentos interpessoais. Nesta fase, é importante ao empreendedor aprender a dar e receber feedbacks, pois eles geram informações importantes para validar as ações tomadas ou para corrigir a rota que a empresa tomou (CLARKE; CORNELISSEN, 2011). Surgem e são instituídos sistemas administrativos e de liderança, para estabelecer as diversas funções e para que haja maior controle e motivação. Há o entendimento de que todos os agentes interajam (se comuniquem) e fortaleçam laços para desenvolver as atividades e alavancar ainda mais a organização.

$\mathrm{Na}$ fase de adolescência organizacional, a empresa está em um período de desenvolvimento, no qual acontece a profissionalização, a delegação de funções e uma maior interdependência dos setores. No entanto, uma das dificuldades desta fase está centrada no processo de transição organizacional: uma revolução dos comportamentos para a profissionalização do negócio. Observa-se que, para a necessária delegação de tarefas, deve haver alteração na forma de liderança e da cultura organizacional. É preciso realizar melhorias nos canais de comunicação (boletins informativos, emails oficiais, reuniões periódicas, dentre outros), para integrar os colaboradores ao negócio, convergir ações, para que a organização consiga transmitir aos seus funcionários o que espera deles, de modo a incentivá-los à constante melhoria dos processos, além de garantir a própria valorização dos mesmos. Omar e Rejab (2011), em um estudo empírico sobre empresas de TI, identificaram que as empresas têm que complementar a educação formal de seus colaboradores para desenvolver habilidades de criatividade, confiança, liderança, pensamento crítico e comunicação.

$\mathrm{Na}$ fase de Plenitude do empreendimento há equilíbrio, com sistemas bem estruturados, e a característica fundamental de comunicação está relacionada à formalização de procedimentos, para assegurar informações suficientes para o desempenho das atividades, de forma clara e objetiva. A comunicação por meios eletrônicos, como e-mail, teleconferência, entre outros, propiciam maior rapidez e eficiência na emissão de informações e consolidação da empresa.

A comunicação é clara.
Todos sabem o que,
por que, quando, como
e quem. O trabalho é
duro, mas pode ser
feito. As pessoas levam
o que se fala ao pé da
letra. Falando em tons
deliberados
comedidos, e
parecem elas
ponderando
importância do que
dizem (ADIZES, 2004,
p. 122).

$\begin{array}{ccc}\text { O Quadro } & 1 \text { sintetiza } & \text { os } \\ \text { conhecimentos e habilidades } & \text { de }\end{array}$ comunicação por fase do CVO de Adizes. As competências de comunicação desenvolvidas em uma etapa não são perdidas ou modificadas de uma fase a outra e podem ser acionadas quando necessário. $\mathrm{O}$ avanço para uma fase posterior não invalida as formas de comunicação das etapas anteriores, porém estas passam a ser realizadas por pessoas 
designadas pelos fundadores, sob sua orientação ou determinação.

Observa-se ainda no Quadro 1 que os conhecimentos e habilidades nas fases iniciais são personificados na figura do empreendedor, pois este também personifica o negócio. Ele é o principal impulsionador do negócio nas fases iniciais, pois é quem cria, compra, produz, vende, acompanha o desempenho do produto ou serviço e dá feedback para os diversos stakeholders (clientes, fornecedores, sociedade, governo, entre outros). À medida que a organização avança para as demais fases, 0 protagonismo operacional do empreendedor deve ser gradativamente substituído pelo protagonismo gerencial, o que irá lhe exigir conhecimentos e habilidades de gestão para o relacionamento com stakeholders em outro nível. Isto fica mais evidente quando se compara a fase de Adolescência, em que a comunicação direta e formal se dá somente com grandes clientes, instituições ou com mercados potenciais; com a fase inicial de Namoro, quando se esforça para conseguir os primeiros clientes, em um ambiente ainda de muita instabilidade e de visão do negócio mais estreita.

\begin{tabular}{|c|c|}
\hline Fase & Conhecimentos e Habilidades \\
\hline Namoro & $\begin{array}{l}\text {-Vender a ideia; } \\
\text {-Compartilhar o sonho com pessoas próximas; } \\
\text {-Convencer adeptos e/ou possíveis financiadores; } \\
\text {-Conseguir primeiros clientes; } \\
\text {-Dar e receber primeiros feedbacks; } \\
\text {-Técnicas de Vendas; } \\
\text {-Preparar e conduzir reuniões; } \\
\text {-Criação e defesa do plano de negócios; } \\
\text {-Identificação e aproveitamento de oportunidades de negócios; } \\
\text {-Construção de redes informais de comunicação. }\end{array}$ \\
\hline Infância & $\begin{array}{l}\text {-Comunicação com subordinados (lidar com hierarquia e poder, porém de maneira informal); } \\
\text {-Troca de conhecimentos e competências com subordinados; } \\
\text {-Persuasão com o uso predominante de linguagem técnica; } \\
\text {-Comunicação informal, porém eficaz; } \\
\text {-Relacionamento interpessoal com subordinados, devido à proximidade; } \\
\text {-Repasse e cobrança de rotinas operacionais; } \\
\text {-Implantar mudanças organizacionais. }\end{array}$ \\
\hline Toca-Toca & $\begin{array}{l}\text {-Comunicação direta, porém com assertividade e polidez; } \\
\text {-Dar e receber feedback; } \\
\text {-Construção e implantação de sistemas formais de comunicação e de gestão; } \\
\text {-Desenvolver e implantar a comunicação entre o staff e os clientes; } \\
\text {-Condução de reuniões; uso de sistemas formais de comunicação; liderança eficaz; } \\
\text {-Implantar mudanças organizacionais; } \\
\text {-Estabelecer e manter relações formais com stakeholders. }\end{array}$ \\
\hline Adolescência & $\begin{array}{l}\text {-Comunicação profissional; } \\
\text {-Delegação de funções; } \\
\text {-Cobrança de resultados por meio de indicadores; } \\
\text {-Uso de sistemas integrados de comunicação com clientes, equipe e fornecedores; } \\
\text {-Comunicação clara da estratégia organizacional, com evidência ao negócio, missão, visão e } \\
\text { valores; } \\
\text {-Comunicação direta e formal somente com grandes clientes, instituições ou com mercados } \\
\text { potenciais; } \\
\text {-Relacionamento institucional direto com sindicatos, sindicatos patronais, serviço público, entre } \\
\text { outros; } \\
\text {-Integração dos funcionários ao negócio. }\end{array}$ \\
\hline Plenitude & -Formalização de rotinas na forma de procedimentos comunicados à organização, clientes e \\
\hline
\end{tabular}


Conhecimentos e habilidades de comunicação para empreendedores nas fases iniciais do ciclo de vida organizacional de Adizes

\begin{tabular}{|c|c|}
\hline Fase & Conhecimentos e Habilidades \\
\hline & $\begin{array}{l}\text { fornecedores; } \\
\text {-Comunicação rápida e eficaz mediada ou não por tecnologias; } \\
\text {-Uso compartilhado da comunicação por toda a empresa; } \\
\text {-Organização e formalização do conhecimento e de sua transmissão aos stakeholders; } \\
\text {-Comunicação direta a grandes públicos, mediada ou não por tecnologias; } \\
\text {-Uso de sistemas integrados de gestão; } \\
\text {--Relacionamento institucional direto ou indireto (por meio de representantes) com sindicatos, } \\
\text { sindicatos patronais, serviço público, entre outros; } \\
\text {-Comunicação indireta com funcionários, realizada por gerentes e supervisores. } \\
\text {-Gerenciar mudanças organizacionais }\end{array}$ \\
\hline
\end{tabular}

Quadro 1 - Síntese dos conhecimentos e habilidade de comunicação por fase do CVO de Adizes

Fonte: Autores.

O distanciamento do empreendedor das atribuições operacionais do negócio também o levará a comunicar internamente com os colaboradores por meio de tecnologias de informação (sites, emails, quadros de avisos, entre outras) ou por meio do corpo gerencial. A comunicação antes direta e pessoal passa gradativamente a uma comunicação de segunda ordem que pode resultar em ruídos/interferências que venham a comprometer a qualidade e o significado do que o empreendedor pretende transmitir. Para isso, terá que criar estratégias de comunicação que garantam a fidelidade dos dados e informações que circulam na organização, o que levará à formalização de rotinas na forma de procedimentos para a comunicação com a organização, clientes e fornecedores, na fase de Plenitude, sob pena de perder competitividade nos negócios.

\section{Conclusões}

$\mathrm{O}$ presente artigo apresentou um conjunto de conhecimentos e habilidades de comunicação para o empreendedor durante as fases de crescimento do ciclo de vida organizacional de Adizes (2004), e sugere que a comunicação deve ajustar-se a cada fase do CVO, para que a organização alcance sucesso. Compreender a comunicação durante o ciclo de vida organizacional favorece ao empreendedor utilizá-la com eficiência em cada fase, pois pode orientar seu desenvolvimento pessoal e o da organização.
A teoria sobre comunicação empresarial posiciona este tema com destaque em relação à sua relevância estratégica e consequentemente para o posicionamento da organização em termos de inovação e desenvolvimento. Ao mesmo tempo, a teoria igualmente aponta que o desenvolvimento do empreendedor requer o acesso e uso de novos conhecimentos e habilidades de comunicação, à medida que a empresa se transforma e lhe exige competências diferentes daquelas que já dominara. Observou-se que a comunicação gradativamente se formaliza ao longo do ciclo de vida organizacional, tornando-se mais impessoal, mediada por tecnologias e ampliando o alcance.

Observou-se que a cada etapa o empreendedor deve acessar e/ou desenvolver novas formas de comunicação para que a organização sobreviva e avance para fases posteriores. Nas fases iniciais a comunicação está centrada na figura do empreendedor e, aos poucos, se torna mais profissional, formal, integrada e mediada por tecnologias. Estas características determinam a evolução da comunicação assim como o desenvolvimento pessoal e profissional do empreendedor.

Espera-se que este estudo teórico possa contribuir para destacar a relevância da comunicação para o desenvolvimento organizacional, bem como para evidenciar o caráter sistêmico e dinâmico dos conhecimentos e habilidades do empreendedor e usá-la para gerar benefícios e crescimento da organização. 
Algumas limitações do trabalho ficam evidentes e merecem um tratamento mais elaborado. Um recorte teórico mais aprofundado pode apontar novas competências não identificadas neste estudo atual, bem como de modelos teóricos consistentes, ainda que a produção científica sobre o tema seja difusa e carente de construtos compartilhados pelos pesquisadores. A falta de uma aplicação prática, com amostras representativas do universo empresarial, impossibilita a validação e generalização dos conhecimentos e habilidades apresentados neste trabalho. $\mathrm{O}$ estudo somente nas fases iniciais do ciclo de vida organizacional não contempla falhas na comunicação nas fases de declínio organizacional, quais competências são perdidas, quais ainda precisam ser acionadas, de modo a compor todo o escopo de existência da organização, do nascimento à morte. O presente estudo ainda abre oportunidades para novos estudos sobre o tema, em empresas que estejam nas diversas fases de desenvolvimento, para validar ou refutar as proposições aqui apresentadas.

\section{Referências}

ADEJIMOLA, A. S. Language, communication and information flow in entrepreneurship. African Journal of Business Management, v. 2, n. 11, p. 201208, Nov 2008.

ADIZES, I. Gerenciando os ciclos de vida das organizações. São Paulo: Prentice Hall, 2004.

BARTOLOMÉ, F. Ninguém confia plenamente no chefe - e daí? In: Comunicação eficaz na empresa: como melhorar o fluxo de informações para tomar decisões corretas (coletânea de artigos da revista Harvard Business Review). $9^{\text {a }}$ Reimp. Rio de Janeiro: Elsevier, 1999.
BORDENAVE, J. E. D. O que é comunicação. $30^{\mathrm{a}}$ reimp. São Paulo: Brasiliense, 2006.

CHURCHILL, N., LEWIS, V. The five stages of small business growth. Harvard Business Review, v.61, n.3, p.30-39, Mai/Jun 1983.

CLARKE, J.; CORNELISSEN, J. Language, Communication, and Socially Situated Cognition in Entrepreneurship. Academy of Management Review, v. 36, n. 4, p. 776-778, Oct 2011.

FARIA, J. C. Administração: teoria e aplicações. São Paulo: Cengage Learning Editores, 2002.

FIGUEIREDO, R.; NASSAR, P. O que é comunicação empresarial? $9^{a}$ reimp. São Paulo: Brasiliense, 2007.

FONSECA, F. B. Estratégias de comunicação: aliadas essenciais para o sucesso dos treinamentos à distância. In: RICARDO, E. J. (Org.) Educação corporativa e educação à distância. Rio de Janeiro: Qualitymark, 2005.

FOOTE, L. M. Honing Crisis Communication Skills: Using Interactive Media and Student-Centered Learning to Develop Agile Leaders. Journal of Management Education, v. 37, n. 1, p. 79-114, 2013.

GRAPEGGIA, M.; MINUZZI, J. Estágios de crescimento da empresa Cacau Show com base no ciclo de vida organizacional. Revista TECAP. v.2, n.2, p. 132-151, 2008.

GREINER, Larry E. Evolução e Revolução no Desenvolvimento das Organizações. Biblioteca Harvard de Administração de Empresas. n.14, 1975.

GUPTA, Yash P.; CHIN, David C. W. Organizational Life Cycle: a Review and Proposed Directions for Research. The 
Conhecimentos e habilidades de comunicação para empreendedores nas fases iniciais do ciclo de vida organizacional de Adizes

Mid-Atlantic Journal of Business. v.30, n.3, p. 269-294, 1994.

HARDY, C. How Institutions Communicate; or How Does Communicating Institutionalize? Management Communication Quarterly, v. 25, n. 1, p. 191-199, Feb 2011.

INVERNIZZI, E.; ROMENTI, S.; FUMAGALLI, M. Identity, communication and change management in Ferrari. Corporate Communications, v. 17, n. 4, p. 483-497, 2012.

KELLER, K. L.; KOTLER, P. Administração de marketing. São Paulo: Atlas, 2006.

LEZANA, A. G. R. Desarrollo regional através del estímulo a las empresas de pequeña dimensión: una propuesta para el diseño y puesta em práctica de programas de promoción. Tese de Doutorado, Universidad Politécnica de Madrid, 1995.

LEE, R.; JONES, O. Networks, communication and learning during business start-up - The creation of cognitive social capital. International Small Business Journal, v. 26, n. 5, p. 559-594, Oct 2008.

LI, J. Political Estrategy of Chinese Private Ventures: an Organizational Life Cycle Framework. International Journal of Entrepreneurship. v.12, p.107-124, 2008.

LI, Y. A. et al. Knowledge communication, exploitation and endogenous innovation: the moderating effects of internal controls in SMEs. R \& D Management, v. 41, n. 2, p. 156-172, Mar 2011

MAXIMIANO, A. C. A. Teoria geral da administração. São Paulo: Atlas, 2006.

MESSERSCHMITT, D. G.; STUCK, B. Effective communication: The what, why, and how of entrepreneurship. Ieee Signal Processing Magazine, v. 25, n. 4, p. 105109, Jul 2008.

METALLO, G.; CUOMO, M. T.; FESTA, G. Relationship management in the business of quality and communication. Total Quality Management \& Business Excellence, v. 18, n. 1-2, p. 119-133, 2007.

MORGAN, G. Imagens da organização. São Paulo: Atlas, 1996.

OMAR, R.; REJAB, I. Entrepreneurial orientation of small and medium enterprises (SMEs) in Malaysian information communication technology (ICT) sector. African Journal of Business Management, v. 5, n. 31, p. 12329-12340, 2011.

PHELPS, R.; ADAMS, R.; BESSANT, J. Life cycles of growing organizations: A review with implications for knowledge and learning. International Journal of Management Reviews. v.9, n.1, p.1-30, 2007.

RAM, B. S.; SELVARAJ, M. Investigations on barriers to the incorporation of Information and Communications Technologies in small scale industries. WSEAS Transactions on Information Science and Applications, v. 9, n. 8, p. 241-250, 2012.

SCOTT, M.; BRUCE, R. Five Stages of Growth in Small Business. Long Range Planning. v.20. n.33, p.45-52, 1987.

SCHUMPETER, J. A. Teoria do Desenvolvimento Econômico. São Paulo: Abril Cultural, 1983.

ULVENBLAD, P.; BERGGREN, E.; WINBORG, J. The role of entrepreneurship education and start-up experience for handling communication and liability of newness. International Journal of Entrepreneurial Behaviour 
and Research, v. 19, n. 2, p. 187-209, 2013.

WANG, Y.; AHMED, P.; FARQUHAR, S. Founders versus Descendants: The Profitability, Growth and Efficiency. Characteristics Comparison in the UK Small and Medium Sized Family Businesses. The Journal of Entrepreneurship, v.16, n.2 p.173-195, 2007. 